\title{
Introduction to EPS and XPS Two Exterior Insulation Used
}

\author{
Xuezhen Zhao \\ Guangzhou ceprei industrial co., LTD, Guangzhou 510610, China. \\ 39843018@qq.com
}

Keywords: the construction energy conservation, EPS exterior insulation system, XPS exterior insulation system, Technical and economic evaluation.

\begin{abstract}
From XPS and EPS of building external thermal insulation system on the advantages and disadvantages of using, EPS more in line with market demand, EPS has good weather resistance and temperature change of dimensional stability, is the most extensive domestic and international building exterior wall thermal insulation materials.
\end{abstract}

\section{The technical parameters of EPS and XPS}

Molding of polystyrene: by polystyrene beads after heating pretest bubble in the mold of heating forming and closed pore structure of polystyrene plastic, commonly referred to as EPS board.

Extruded polystyrene board, polystyrene resin or its copolymer as main ingredient, add a small amount of additives, made by heating extrusion molding with obturator structure of rigid foam plank, often referred to as XPS board.

Table. 1 The thermal parameters of EPS and XPS

\begin{tabular}{|c|c|c|c|c|c|}
\hline $\begin{array}{c}\text { The name } \\
\text { of the } \\
\text { material }\end{array}$ & $\begin{array}{c}\text { Coefficient of } \\
\text { thermal } \\
\text { conductivity } \\
{[/(\mathrm{m} \cdot \mathrm{K})]}\end{array}$ & $\begin{array}{c}\text { Heat storage } \\
\text { coefficient } \\
{\left[\mathrm{W} /\left(\mathrm{m}^{2} \cdot \mathrm{K}\right)\right]}\end{array}$ & $\begin{array}{c}\text { Correction } \\
\text { coefficient }\end{array}$ & $\begin{array}{c}\text { Coefficient of } \\
\text { thermal } \\
\text { conductivity } \\
\text { calculation } \\
\text { values } \\
{[\mathrm{W} /(\mathrm{m} \cdot \mathrm{K})]}\end{array}$ & $\begin{array}{c}\text { Heat storage } \\
\text { coefficient } \\
\text { calculated } \\
\text { value } \\
{\left[\mathrm{W} /\left(\mathrm{m}^{2} \cdot \mathrm{K}\right)\right]}\end{array}$ \\
\hline EPS board & 0.039 & 0.36 & 1.05 & 0.041 & 0.37 \\
\hline XPS board & 0.030 & 0.32 & 1.2 & 0.036 & 0.38 \\
\hline
\end{tabular}

\section{The EPS and XPS exterior insulation system}

\subsection{Economy}

XPS of heat coefficient is smaller than EPS (see chart), and has high heat resistance, low linear, the characteristics of low expansion ratio, The structure of the obturator rate reached more than 99\%, forming a vacuum layer, avoid air flow cooling, to ensure that the insulation performance of lasting and stable, compared with the $80 \%$ EPS closed porosity, lead is self-evident. Practice has proved a 30 $\mathrm{mm}$ thick XPS insulation board, the heat preservation effect of $50 \mathrm{~mm}$ thick EPS insulation board, 120 mm thick cement perlite. So, in order to achieve the same effect of heat preservation, XPS insulation thickness can be thinner than EPS around 30\%, but as a result of XPS EPS is the price of 2 times the left and right sides, so the economy is not as good as EPS of XPS. 


\subsection{Thermal Stability}

According to the national standard for testing, the current domestic use (including foreign) XPS deformation of $1.2 \%$ or so, and EPS within $0.5 \%$, so using XPS board building external thermal insulation system of shielding mortar and coating is easy to crack. And EPS has good weather resistance and temperature changes in the size of the stability, is the most extensive domestic and international building exterior wall thermal insulation materials. The main reason is: EPS is generally free foam under the normal pressure, and then through the middle maturation, molding foam (final), large plate curing process, such as time experience for several days, the basic is the circular hole structure, hole between fusion is better, so is in a good dimensional stability. And XPS foam is almost in an instant, suddenly is due to high temperature and high pressure to atmospheric pressure, foaming process difficult to control, if the cooling is not good, cold also can cause stress concentration, and at the same time of foam, and squeezed by leveling machine, make its basically can only on the length and width direction. therefore, the internal hole structured spindle, the spindle hole tip under the effect of external force (such as temperature stress, etc.), can produce stress concentration, to a certain degree of stress concentration will cause deformation, so the poor dimensional stability.

\subsection{Can Be Viscous}

Because of the different production process, EPS porosity is larger than XPS, namely EPS insulation board surface roughness than XPS, but because of this, plus the EPS density is small, EPS board can be viscous than XPS. Although now construction market also appeared a plane skin of XPS board, but required by the insulation industry related interface agent and XPS standards, there is no standard or landmark. XPS board commonly so insulated facade is easy to crack, empty drum, fall off.

\subsection{Apparent Quality}

Through the external thermal insulation construction technology guidance, insulation board, after the completion of paste for surface grinding, leveling, but because of XPS intensity is high, lead to burnish is not easy to control, deformed plate is not easy to processing at the scene, so generally apparent quality of XPS plate facade as EPS board.

\subsection{Permeability}

XPS board of steam trap performance is good, low water absorption, but as a result of external thermal insulation system is between a number of wall insulation board splicing and structure must be the three-dimensional structure of the cavity, so high permeability of XPS board can be used for exterior insulation, become its fatal flaw, because the plate seam, moisture resistance, we could not to improve or avoid water imbibition, and plate is not through steam, it hinders the moisture in the wall, through plenty of moisture will gather in the cavity between the wall and XPS insulation, easily to produce the water vapor concentration in the plate joints and thermal insulation layer deformation and paste layer falls off, directly affects the service life of exterior insulation system, and the safety of the external wall thermal insulation. And EPS plate of special material performance, can cut off the rain, and can make the moisture in the wall through, effectively resolves the problem of the structure of the permeability.

\section{Summary}

About the relevant technology of exterior insulation, standards, specifications, atlas also gradually improve. At present the Chinese market more than $80 \%$ of the building wall thermal insulation are used EPS board, and all the relevant codes and standards are established on the basis of EPS board, so the EPS thermal insulation system more mature both at home and abroad. And thermal insulation system, XPS plate will face more improvement and practice. 


\section{References}

[1] The external wall thermal insulation engineering discipline JGJ144-2004

[2] The construction quality acceptance of building energy conservation engineering GB50411-2007

[3] Xiao-jun Liu, Engineering economics, China building industry press, 2003 